\title{
Pollinators and Global Food Security: the Need for Holistic Global Stewardship
}

\author{
Jeroen P. van der Sluijs $s^{1,2,3} \cdot$ Nora S. Vaage ${ }^{1,4}$
}

Accepted: 15 April 2016/Published online: 9 May 2016

(C) Springer International Publishing Switzerland 2016

\begin{abstract}
Over the past decades, both wild and domesticated insect pollinators are in dramatic decline, which puts at stake the existence of species, ecosystem resilience and global food security. Globally, 87 of major food crops depend on animal pollination. Together these account for $35 \%$ of the world food production volume. Pollinator mediated crops are indispensable for essential micronutrients in the human diet. Many ornamental plants as well as crops for fibre, fodder, biofuels, timber and phytopharmaceuticals also depend on insect pollinators. This article aims to map the current situation of pollinators worldwide, with a focus on the critical role of pollinators in the human food chain and ecosystem sustainability, their intrinsic and extrinsic value, as well as the causes of their declines and the interventions needed to conserve them, in order to develop an argument for the importance of conserving and restoring pollinator populations and diversity. The present pollinator crisis threatens global and local food security, can worsen the problems of hidden hunger, erodes ecosystem resilience, and can destabilise ecosystems that form our life support system. An integrated approach that simultaneously addresses the key drivers is needed. This includes creation and restoration of floral and nesting resources, a global phase out of prophylactic use of neonicotinoids and fipronil, improvement of test protocols in authorisation of agrochemicals, and restoration and maintenance of independence in regulatory science. The authors argue that an international treaty for global pollinator stewardship and pollinator ecosystem restoration should be initiated in order to systemically counteract the current crisis.
\end{abstract}

Jeroen P. van der Sluijs

Jeroen.Sluijs@uib.no

1 Centre for the Study of the Sciences and the Humanities, University of Bergen, Postboks 7805, 5020 Bergen, Norway

2 Department of Chemistry, University of Bergen, Bergen, Norway

3 Copernicus Institute of Sustainable Development, Environmental Sciences, Utrecht University, Utrecht, The Netherlands

4 Centre for Digital Life Norway, Norwegian University of Science and Technology, Trondheim, Norway 
Keywords Pollinator decline $\cdot$ Ecosystem services $\cdot$ Food security $\cdot$ Honeybees $\cdot$ Pollination

\begin{abstract}
"The way humanity manages or mismanages its nature-based assets, including pollinators, will in part define our collective future in the 21st century. The fact is that of the 100 crop species that provide $90 \%$ of the world's food, over 70 are pollinated by bees." (Achim Steiner, Director of UNEP, UNEP 2011).
\end{abstract}

\title{
Introduction
}

The Earth's entomofauna is in an ongoing state of collapse (Bijleveld van Lexmond et al. 2015). This has a number of repercussions including loss of biodiversity and impairment of ecosystem resilience, also outside of the insect realm, and poses a global risk to pollination by insects. Pollinators perform key ecosystem services for ecosystem functioning and global food security. The projected world population of $9-10$ billion by 2050, accelerating consumption, negative climate impacts on food production, global pollinator decline (Vanbergen and the Insect Pollinators Initiative 2013) and the failure to end hunger and malnutrition for the present population (Ehrlich and Harte 2015) mean that food security is a pressing challenge. Key dimensions of global food security are availability, accessibility, and utilisation, with a focus on nutritional well-being, stability, and sustainability (Berry et al. 2015; FAO 1996). Global food security, also reliant on several other factors such as weather, political stability, and a non-corrupt infrastructure, is critically dependent on pollinator services (Vanbergen and the Insect Pollinators Initiative 2013; Van der Sluijs et al. 2013a; Chagnon et al. 2015; Bailes et al. 2015) and this also is the case for nutritional wellbeing (Nicole 2015; Ellis et al. 2015). The apparent complexity and multi-causality of pollinator decline and inadequate monitoring systems, particularly for wild species, means that controversy is rife about the scale of this global problem and how to mitigate it. The demand for, and consumption of, animal pollinated crops is currently rising at a greater rate than managed honeybee colonies (Aizen and Harder 2009). Domesticated bees increasingly suffer from bee disorders (Potts et al. 2010; UNEP 2010; Van der Sluijs et al. 2013a), and regionally severe declines have occurred in the USA (59\% loss of colonies between 1947 and 2005 ) and central Europe ( $25 \%$ loss of colonies between 1985 and 2005, according to Potts et al. 2010). For the rest of the globe, few data exist to confirm declines, in particular of wild pollinators (Goulson et al. 2015). However, the consensus among experts is that wild pollinators are indeed declining rapidly as a result of multiple stressors including large-scale prophylactic use of systemic insecticides, habitat destruction from changing land use, pollution, and climate change (Potts et al. 2010; Vanbergen and the Insect Pollinators Initiative 2013; Goulson et al. 2015; EASAC 2015). A holistic approach that aims at preserving biodiversity and ecosystem integrity is necessary in order to ensure ecosystem resilience (Senapathi et al. 2015).

This article aims to explore the importance of pollinators in food production, and review the evidence that their decline threatens human food security, food diversity and ecosystem resilience. This is done through discussion of present day knowledge on various pollinators and their impact on food crops, causes for the decline of important insect pollinators, and a range of suggested solutions as well as their potential problems and ethical implications. The authors argue for an international, integrated approach that takes into account the intrinsic as well as extrinsic value of pollinators, and propose that coordinated global stewardship is needed in order to implement such solutions timely and effectively. 


\section{On Pollinators and their Importance}

Pollination is an essential regulating, supporting and cultural ecosystem service (Chagnon et al. 2015). It comprises an integrated system of interactions that links earth's vegetation, wildlife and human welfare (Kevan and Menzel 2012). Many crops and wild plants require pollination for the setting of fruits and seeds. Pollination is the active and passive transfer of pollen within or between flowers (in biological terms: the transport of pollen from producing anthers to receiving stigma of flowers). Forms of pollination include passive self-pollination, wind pollination, and animal mediated pollination (by invertebrates such as bees, mammals such as bats, and birds such as hummingbirds). Self-pollination occurs in some plant species but is rarely the dominant pollination route. Wind pollination is the dominant pollination route for less than $10 \%$ of flowering plants. Up to $94 \%$ of all flowering plants on earth benefit from animal pollination for reproduction and evolution (Vanbergen and the Insect Pollinators Initiative 2013; see also Ollerton et al. 2011).

Globally, 87 of humanity's major food crops depend on animal pollination (Klein et al. 2007). These include vegetable, fruit, nut, and edible oil and proteinaceous crops, as well as spices and condiments (Maxim and Van der Sluijs 2013a). Many fibre and fodder crops also depend on insect pollination, the latter indicating that the loss of insect pollinators can also indirectly affect the production of livestock agriculture. Biofuel crops (e.g., canola) and many trees that are grown or harvested for timber production also require animal pollination. The majority of plants used for production of phytopharmaceuticals also depend on pollinators. The same goes for the majority of ornamental plants. Box 1 provides an overview of important pollinator mediated crops.

Box 1: Crops that depend on insect pollination

Human food crops that depend on and/or are improved by insect pollination include vegetable crops, such as melons, cucumbers, pumpkins and squashes; fruit crops, such as apples, peaches, kiwi fruit, passion fruit, mango, avocado, plums, pears, cherries, apricot, cocoa, coffee, raspberry, blackberry, cloudberry, dewberry, rowanberry, cranberry, starfruit, durian, Japanese medlar, and rose hips; nut crops, such as almond, cashew nut, and macadamia; edible oil and proteinaceous crops, such as canola, sunflower and turnip rape; and spices and condiments, such as vanilla, coriander, cardamom and fennel (Maxim and Van der Sluijs 2013a, b). Together these account for $35 \%$ of the world food production volume (Klein et al. 2007).

Many fibre crops (such as cotton, flax and hemp), fodder crops for cattle breeding (such as alfalfa and soy), biofuel crops (e.g., canola), timber crops (e.g., eucalyptus), ornamental plants, and plants for the production of phytopharmaceuticals (e.g., Cinchona from which quinine is made, which is widely used for the treatment of malaria) also depend on insect pollination. Overall, around $75 \%$ of all crop species benefits from greater yields from animal pollination.

Pollinators can also improve the quality (especially fruit quality), shelf life and commercial value (for instance, poorly pollinated strawberries are malformed and look less attractive for consumers) of crops (Klatt et al. 2014) and increase the genetic diversity of wild flowering plants (Benadi et al. 2013). As such, they are of high economic value, insect pollinators estimated to an annual worth of $€ 153$ billion for the year of 2005 (Gallai et al. 2009). Gallai et al. (2009) also estimated that the value of pollinator-dependent crops averaged $761 €$ per ton, whereas other crop categories including cereals and roots and tubers averaged $151 €$. In providing diversity, nutritional value and delectable flavours, these crops contribute substantially to the quality of life and food culture of people around the world (Chagnon et al. 2015). Production and consumption of pollinator-dependent crops are on the rise worldwide, although particularly in the developed world $(16.7 \%$, versus $9.4 \%$ increase in the developing world 
from 1961 to 2006; see Aizen and Harder 2009; Chagnon et al. 2015). Agriculture, in addition to ensuring nourishment for people worldwide today, provides livelihoods for about $40 \%$ of the global population. The pollinator decline may potentially lead to the loss or decrease of a substantial amount of crops of high economic and cultural value.

Further, although the majority of calories in the human diet stems from wind-pollinated cereals, pollinator mediated crops are of key importance in providing essential nutrients in the human food supply: in terms of nutrients in the human diet they account for more than $90 \%$ of vitamin C, $100 \%$ of Lycopene and almost $100 \%$ of the antioxidants $\beta$-cryptoxanthin and $\beta$ tocopherol, the majority of the lipids (74\%), vitamin A (>70\%) and related carotenoids (98\%), calcium (58\%) and fluoride (62\%), and a large portion of folic acid (55\%). In total, pollinator mediated crops account for about $40 \%$ of global nutrient supply for humans (Eilers et al. 2011). At present, an estimated 2 billion people suffer from deficiencies of such micronutrients, also known as hidden hunger (IFPRI 2014; Nicole 2015).

The impacts of chronic vitamin and mineral deficiencies on health and wellbeing are both serious and abiding. Hidden hunger limits people's ability to survive and thrive, in some cases causing irreversible health effects. This type of malnutrition can occur in individuals that have no energy deficits, and can coexist with obesity. At present, it is mainly a problem in developing countries and holds these countries back in a cycle of malnutrition, poor health, persistent poverty, and lost productivity (IFPRI 2014). Evidence is mounting that if the current trends in global pollinator loss continue, the problems of hidden hunger are likely to further increase (Eilers et al. 2011; Ellis et al. 2015; Nicole 2015). A recent study by Ellis et al. (2015) found that composition of local diets are a key factor in sensitivity of hidden hunger to pollinator loss, and that in four developing countries and across five nutrients studied, up to $56 \%$ (Mozambique) of populations could become newly at risk if pollinators were removed. A key nutrient here is vitamin A: more than two thirds of the vitamin A in children's diets stems from fruits and vegetables, many of which depend strongly on pollinators. In addition to sustained availability of food, the UN definition of food security points to satisfaction of both nutritional needs and dietary preferences (FAO 1996). This, as is stressed in the definition, is a global issue.

Pollination is also essential for sustaining the diet of wildlife because many bird and mammal species feed on wild fruit (e.g., birds that feed on all kinds of wild berries in forests), wild nuts and seeds of wild plants. If all insect pollinators were removed, this would result in a drastic decline in setting of wild fruits, nuts and seeds, which would affect all species that depend on it. Herbivores can also suffer from food depletion if pollinator dependent plants on which these herbivores depend can no longer reproduce.

Pollinating services are provided by a wide range of animal species, mostly insects including honeybees, bumblebees, solitary bees, stingless bees, hover flies, butterflies, wasps, moths, beetles, midges, and other invertebrates, but also some vertebrates are known to pollinate such as bats, squirrels, parrots, hummingbirds, some primates and humans (hand pollination) (Buchmann and Nabhan 1997; Allen-Wardel et al. 1998; Klein et al. 2007). For agricultural crops, bees are the most important pollinators (UNEP 2010). In the past, most of the credit has been given to domestic honeybees. However, recent studies have shown that wild pollinators are more important contributors to global crop pollination than previously assumed (Breeze et al. 2011). Estimates for the UK indicate that managed honeybees (Apis mellifera) pollinate approximately no more than one third of the crops. Among the unmanaged pollinators, wild bees are important. Globally, over 25,000 species of bees are known (Chagnon et al. 2015). However, many insects other than bees are also efficient pollinators, providing $39 \%$ of visits to crop flowers (Rader et al. 2015). Wild insect pollinator species are 
regarded as the most effective pollinators of fruit crops (Chagnon et al. 2015). Klein et al. (2007) pointed to nine pollinator-dependent crops that did not exhibit proof of honeybee presence, and that three of these (atemoya, passion fruit and vanilla) are now hand-pollinated in parts of the world, due in part to the reduced presence of the relevant wild pollinators.

Humankind and bees have a long-standing relationship. The history of beekeeping goes back to pre-agricultural times (Dams 1978; Pattinson 2012). Since the beginning of agriculture, large-scale beekeeping has existed (Bloch et al. 2010; Ebert 2011). Bees and apiary products have large extrinsic value connected to their wide range of uses, including the pharmacological use of propolis against infections (Banskota et al. 2001) and honey to improve healing times for burn wounds (Jull et al. 2008) as well as inspiration for scientific and technological research on navigation and robotic flight (Srinivasan 2011). Honey has been of culinary importance for millennia, and is still a key ingredient, e.g., for traditional patisseries (Ellis 2014). Bees are also strong cultural indicators, inspiring poetry and metaphors (e.g., Rogers and Sleigh 2012), aesthetic expressions (springs filled with buzzing bumblebees), and cultural and even political values (Southwood and Richard 1977); bee colonies form a super organism, and emergent joint decision making in bee colonies inspires democratic thought on consensus decision making (see Conradt and Roper 2005). Domestic bees as such have many important properties in addition to their role as pollinators. While most of these properties and associated values are extrinsic, some are arguably intrinsic ends-in-themselves, and contribute to the conceptualisation of these species as worth protecting for their own sake, not for their instrumental value alone. Other insects also have aesthetic, nutritional and cultural properties and economic value. Jewellery and decorations shaped in the form of insects, or made from them, has been used around the world since ancient times, and butterflies, moths and beetles have inspired sayings, myths and even religious reverence (Southwood and Richard 1977). The value of insects for humans is deeply embedded in our culture and in natural systems, which may easily be forgotten in discussions of pollinators as providers of an ecosystem service. Both the intrinsic and extrinsic value of pollinators should be taken into account when mitigating the problem of their global decline (Pearson 2016).

The world's entomofauna, in general, does not induce much concern from NGOs or citizens. This is perhaps in part due to the idea of all insects as pests - even indisputably beneficial ones, such as honeybees, might also sting you (Southwood and Richard 1977) — and in part to the distance in the genetic tree of life between humans and insects and associated uncertainty as to whether concepts such as wellbeing and pain are applicable to insects. However, as awareness is increasing about the critical state of pollinators, grassroots initiatives are being introduced in local contexts aiming to protect pollinators, with bees as their most iconic representatives.

\section{Global Pollinator Decline and its Causes}

Over the past decades, both wild and domesticated pollinators have been in dramatic decline (Potts et al. 2010). Biesmeijer et al. (2006) reported parallel declines (pre- versus post 1980) in pollinators (mainly bees, but also hoverflies) and insect-pollinated plants in Britain and the Netherlands. In the US, dramatic widespread decline of bumblebees has been observed: the relative abundances of four previously common bumblebee species have declined by up to $96 \%$. Their surveyed geographic ranges have contracted by $23-87 \%$, some within the last 20 years (Cameron et al. 2011). Managed honeybees have also been found to be in decline 
both in the US (Allen-Wardel et al. 1998) and in Europe (Potts et al. 2010). In other parts of the world such as China and Argentina, the trend moves in the other direction as the number of managed hives is increasing at a pace higher than the number of colony collapses (Goulson et al. 2015). The decline of wild pollinators has since the 1990s forced orchard farmers in southwest China to employ human hand-pollinators, which are markedly less effective and economically unsustainable (Partap and Ya 2012) (with the exception of some fruit varieties where hand pollination has economic advantages, such as some pear varieties where male and female trees do not flower simultaneously). In Australia, strict quarantine is enforced in order to ensure that invasive species (whether competing bees, pathogens or parasites) do not disturb existing honeybee populations, and there is at this point no confirmed report of increases in colony collapses. In Africa, Egyptian beekeepers have reported colony collapses (UNEP 2010). However, few data exist on pollinators in these regions, particularly regarding wild species (Vanbergen and the Insect Pollinators Initiative 2013).

Increasing honeybee disorders, abnormally high winter colony losses, and reduced lifespan of honeybee queens has been observed over the past decades (Van der Sluijs et al. 2013a, Pisa et al. 2015). So far, research points in the direction that no single cause explains the global increase in winter colony losses. All viruses and other pathogens that have been linked to colony collapse are present year-round also in healthy colonies, which implies that the presence of these pathogens alone does not drive the collapse of colonies (Runckel et al. 2011). It seems more likely to be a combination of reciprocally enhancing causes (Goulson 2015; Vanbergen and the Insect Pollinators Initiative 2013). Among those, the large-scale introduction of systemic insecticides, in particular the so-called neonicotinoids has gained more weight (Van der Sluijs et al. 2015; EASAC 2015).

The global decline of unmanaged insect pollinators is part of a larger global catastrophic decline of insects and arthropods in general (Bijleveld van Lexmond et al. 2015). Evidence for decreased crop yields and species diversity due to decreased pollination has not yet been provided on a global scale, but is indicated through regional studies (mostly available for Europe and the US; see e.g., Chagnon et al. 2015). The root causes of the ongoing collapse of the Earth's pollinators (and entomofauna at large) include the intensification of agriculture with its accompanying loss of natural habitats and loss of foraging and nesting resources, large scale use of agrochemicals such as insecticides, fungicides, herbicides, and fertilizers, nitrogen deposition, climate change, invasive species, spread of pathogens, the manifold increase in roads and motorised traffic, and the continent-wide nocturnal light pollution (Bijleveld van Lexmond et al. 2015; Vanbergen and the Insect Pollinators Initiative 2013). Within this larger context, pollinators deserve particular consideration due to their vital ecosystem function and critical role in ensuring local and global food security. In the following paragraphs, we further explore the key drivers.

\section{Loss of Habitat, Foraging and Nesting Resources}

Bees and other pollinators forage on flowers that provide them with pollen (proteins and lipids) and nectar (carbohydrates). Honeybee colonies typically consist of 40.000 bees and worker bees have a lifespan of roughly 4 weeks. This means that a continuous brood cycle from eggs to larvae to bees needs to be sustained over the entire foraging season while a food stock sufficient for overwintering of the colony also needs to be collected. Fresh pollen of sufficient nutritional quality and of sufficient quantity and diversity needs be available throughout the foraging season. This requires a tremendous and continuous influx of 
fresh pollen into the hive as the main protein resource. A single honeybee hive can visit more than 2 million flowers per day. Quantity and quality of pollen, nectar and water as well as temporal and spatial distribution of these foraging resources are essential for colony survival.

Land use change and landscape changes have drastically reduced the number and diversity of wild flowers, especially in agricultural landscapes (Klein et al. 2007). Where hedgerows and field margins used to be rich in flowering plants (including flowering trees and shrubs) and a diversity of flowering weeds grew between crops (e.g., cornflower, Centaurea cyanus, in corn fields and redshank, Persicaria maculosa, in potato fields), modern large-scale agriculture with massive monoculture and massive use of herbicides has drastically reduced the availability and diversity of wild flowers. The use of genetically modified bulk crops also negatively impact pollinators in several ways. Herbicide tolerant GM crops go hand in hand with massive use of herbicides, which eliminates flowering weeds and weeds that act as host plants from the agricultural landscape. Insect resistant GM crops such as those that produce Bacillus thuringiensis (Bt) toxins may reduce insecticide use and could reduce the pressure on some pollinators (e.g., bees) but can harm other pollinators (e.g., some butterflies).

Depletion of floral resources is further reinforced by large-scale anthropogenic water and air pollution with reactive nitrogen. The present excess of reactive nitrogen has two main causes: agriculture and livestock production (fertilizer and manure), and the combustion of fossil fuels. Atmospheric reactive nitrogen deposits and accumulates in soils, including soils of nature areas. This accumulation of nitrogen in soils drives changes in species composition across the whole range of different ecosystem types. It alters the competitive interactions that lead to composition change and/or makes conditions unfavourable for some species (Bobbink et al. 2010). Nitrogen accumulation affects pollinators because it reduces the diversity and quantity of flowering plants in the landscape.

For solitary bees and other wild bees, micro-habitats that are suitable for nesting occur more in patchy and diverse landscapes than in monotonous landscapes. With massive changes over the past century in land use, landscapes, and agricultural practices, many nesting resources and micro-habitats have disappeared, which has contributed to global insect pollinator decline (Goulson et al. 2015).

Climate change is a further driver of habitat destruction. Climate and hydrology set the general conditions for the occurrence and thriving of wild species. With global warming, the Earth's climate zones shift pole-wards. Pollinators and the flowering plant species on which they depend that cannot compensate for this or have limited abilities to keep up with the rate of change are at risk (Potts et al. 2010). Climate change also shifts the growing season, meaning that plants start flowering earlier in the season. As a consequence, gaps can occur in the required continuous availability of fresh pollen throughout the foraging season of honeybee colonies.

For managed honeybees in America and Europe, the introduction of the Varroa Destructor mite (an invasive species originally from Asia) and the global spread of bee pathogens that came with the globalisation of trade in bee queens, has caused major problems in beekeeping and bee health. For honeybee declines it is now widely held that the observed trends can be explained by combined stress from parasites, pesticides and lack of flowers (Goulson et al. 2015). Due to the complexity of these causes, there are few and uncertain numbers on how much of the decline is caused by the respective factors. 


\section{Large-Scale Prophylactic Use of Systemic Neonicotinoid Insecticides}

Neonicotinoids are a new generation of insecticides introduced in the early 1990s (Maxim and Van der Sluijs 2013a). These chemicals have a substantially lower acute toxicity to humans, birds and mammals than the older insecticides which they replaced. However, evidence is mounting that these chemicals play a key role in bee disorders and pollinator decline observed over the past decades (EASAC 2015; Krupke and Long 2015; Rundlöf et al. 2015; SanchezBayo 2014; Van der Sluijs et al. 2013a, 2015; Williams et al. 2015).

Neonicotinoids are widely applied as a coating to seeds of crops or as treatment of soil. The most widely used GM crops are also routinely coated with neonicotinoids. These neurotoxic agrochemicals act systemically: during growth the active substance is taken up by the roots and makes the whole plant toxic to insects for a long period. Unintendedly, neonicotinoids also end up in nectar and pollen, which are the food sources for bees (Botías et al. 2015; Maxim and Van der Sluijs 2013a).

Neonicotinoids are persistent in soil and water, remain in the environment for a long time, and spread quickly through surface water (Bonmatin et al. 2015). Through systemic uptake it also contaminates wild flowers (Botías et al. 2015). In the Netherlands levels of imidacloprid (the most widely used neonicotinoid, introduced in 1994 as an insecticide to coat sunflower seeds with before planting) far in excess of what is considered safe for aquatic ecosystems have been measured continually in the surface water since 2004 (Van Dijk et al. 2013), 1000 to 25,000 times the Maximum Permissible Concentration in the Netherlands of $13 \mathrm{ng}^{-1}$. Van Dijk et al. (2013) found that high levels of imidacloprid in surface water consistently correlate to low aquatic insect abundance. Several non-bee insect pollinators have an aquatic larval stage and are thus affected by this. Many insect pollinators, including honeybees and bumblebees, forage on surface water and can thus be exposed to neonicotinoid residues. For honeybees, imidacloprid is more than 7,000 times more toxic than the insecticide DDT (acute toxicity). Furthermore, it gradually becomes lethal to insects as a result of prolonged exposure to extremely low levels (chronic toxicity) and has behaviour-disturbing effects on almost all non-target insect species. In low dose, it disturbs flight behaviour, navigation, brood development and impairs individual and social grooming. Synergistic effects with other agrochemicals have been found (Van der Sluijs et al. 2013a; Pisa et al. 2015).

After their introduction to the market in the early 1990s by Bayer Cropscience, neonicotinoid use grew rapidly to occupy more than a quarter of the world market of insecticides within less than 15 years (Jeschke and Nauen 2008; Jeschke et al. 2011; Simon-Delso et al. 2015; Van der Sluijs et al. 2013a). By 2010, imidacloprid was registered as an insecticide in more than 120 countries (Maxim and Van der Sluijs 2013a). Neonicotinoids are now the most commonly used and fastest growing type of insecticide in the world. In Europe neonicotinoids are authorised for hundreds of crops (Simon-Delso et al. 2015).

The role of neonicotinoids in worldwide honeybee disorders has led to strong controversies (Maxim and Van der Sluijs 2013a). Major declines of honeybee colonies have been reported in France since 1994. Some years later other parts of the world experienced similar sudden colony losses. Colony collapse disorder soon became a global phenomenon, which coincides with the booming world-wide use of neonicotinoids. During the French honeybee crisis in the 1990s beekeepers and scientists involved in public research suspected the neonicotinoid imidacloprid. Representatives from Bayer Cropscience (the producer of imidacloprid) and 
the French Food Safety Authority (AFSSA) denied a causal relationship between imidacloprid and the honeybee decline, and pointed at many other factors that could also be to blame. A French expert committee (CST 2003) concluded that imidacloprid was indeed likely to be implied in the bee losses and the Minister of Agriculture banned its use in sunflower and maize seed-dressing as a precaution (Maxim and Van der Sluijs 2007, 2010, 2013a). Since then, an ever increasing number of studies with contradictory conclusions appeared, and two camps emerged: (mainly) industry scientists pointing at the Varroa Destructor mite as the main cause and academic scientists pointing at a complex of causes that synergistically reinforce one another, with neonicotinoids as a key factor. The controversy has led to a vehement societal conflict between beekeepers, environmental NGO's, industry and regulatory agencies (including EFSA and US-EPA) around the globe, with a call for a global ban on neonicotinoids and court cases in many countries. Some countries, such as Italy and Slovenia, decided early on to completely ban the use of neonicotinoids for seed dressing, even while the science was still inconclusive and contested. The EU followed in 2013 with a 2-year moratorium on the use of 3 neonicotinoids in crops attractive to bees (Maxim and Van der Sluijs 2013a; EASAC 2015; the ban is currently being reviewed by EFSA scientists). Fipronil, another systemic neurotoxic insecticide implied in bee disorders and also widely used, was considered for inclusion in the EU moratorium, but was instead subjected to restrictions (EFSA 2015; Pisa et al. 2015).

One element of the controversy concerns the chronic toxicity model. The regulatory science assumes that there is a dose below which no harmful effects will occur. However, an early study by Suchail et al. (2001) found chronic effects on bees at unexpectedly low dose, 1000× lower than in acute toxicity studies. The study was heavily attacked by industry scientists (see Maxim and Van der Sluijs 2013a, b). Recently Tennekes (2010) concluded that the toxicity of neonicotinoids is reinforced by exposure time and postulated a chronic toxicity model based on Haber's law, originally developed to characterise the toxicity of neurotoxic chemical warfare gases, which states that the prolonged exposure to diminishing concentrations of toxins over time produces a constant (irreversible) toxic effect (ct = constant). In other words: toxicity of such chemicals is reinforced by exposure time: the longer the exposure time, the lower the daily dose required to produce a chronic lethal effect. A lower daily dose thus means a longer time to the mortal effect. Only a (chronic) dose where the time to mortality would exceed the natural lifespan of the insect could be considered non-lethal, but it can still produce sub-lethal harmful effects. The regulatory tests prescribed for chronic toxicity in amongst others the EU and North America are limited to a 10 day chronic toxicity test, which is excessively short in view of Haber's law and the life span of pollinators and thus does not protect pollinators. Tennekes's findings are consistent with Suchail et al.'s empirical findings. Tennekes's paper was criticised by Bayer scientists (Maus and Nauen 2011) but later corroborated by empirical data (Tennekes and Sanchez-Bayo 2011, 2013). While it is still contested by industry scientists, the European Food Safety Authority (EFSA) Panel on Plant Protection Products and their Residues (EFSA 2013) adopted the new chronic toxicity model as valid in their recent Scientific Opinion on the science behind the development of a risk assessment of Plant Protection Products on bees. They did not, however, change the prescribed duration of the chronic toxicity test for bees, which is still 10 days, while the life span of a healthy overwintering worker honeybee can be up to 6 months and the lifetime of a healthy honeybee queen up to 4 years.

Another item of dissent stems from contradicting findings of lab studies and field studies: The present day European protocols for the authorisation of plant protection 
products give more weight to findings from field studies than to lab studies and semi field studies (Maxim and Van der Sluijs 2013b). This reflects the severe influence of the industry on the regulation (see also Boone et al. 2014). While many lab studies and semi field studies found harmful effects of neonicotinoids to bees at field realistic dose (Maxim and Van der Sluijs 2013a), most of the published field studies did not confirm these effects. Field studies have so far mostly been industry sponsored, and these studies have been heavily criticised for lacking the statistical power to prove absence of effects (e.g., Van der Sluijs et al. 2013a). Many flaws in experimental set-up of field studies used for authorisation have been pointed out (Goulson 2015). In 2010, for example, the US Environmental Protection Agency reclassified the Cutler and Scott-Dupree (2007) field study (on the basis of which the neonicotinoid clothianidin has been authorised in the US, Canada and Europe) as "invalid" because of the severe shortcomings identified in the test set-up, such as too short distance between case and control fields, and too small scale and follow-up time of the experiment. Given that bees forage in a 3 to $9 \mathrm{~km}$ radius around the hive, it is almost impossible to design a reproducible field test with sufficient statistical power. Still many countries base the market authorisation of neonicotinoids on the findings of flawed field studies, because the only criterion for inclusion or exclusion is whether the study has a Good Laboratory Practice (GLP) certificate, which is a quality system promulgated by the OECD. GLP has been criticised because it does not address quality of experimental set up, nor does it address the statistical power of the experiment (Maxim and Van der Sluijs 2013b). Regulations such as those found in Italy and Slovenia, as well as the EU moratorium on 3 neonicotinoids in 2013-present, constitute constructive steps, but are far from enough to counteract the local and global trends of pollinator decline.

\section{Discussion}

This article has presented evidence for the severity and complexity of the current pollinator situation. Because pollinator decline has multiple interacting causes it cannot be solved by tackling a single driver isolated from the other factors. An integrated approach that simultaneously addresses the key drivers is needed in order to counteract pollinator decline and establish a balance that ensures food security and ecosystem integrity for the future.

\section{Complexity and Uncertainty}

Pollinator decline is an issue that is characterised by complexity, deep uncertainty, high stakes and urgency. As such, it has all the characteristics of a post-normal science issue (see also Maxim and Van der Sluijs 2007). The uncertainty of the pollinator situation consists partially in the fact that evidence about their numbers and wellbeing has only been provided locally and in certain regions of the world, in most cases focusing on certain groups of pollinators. Historic data and systematic monitoring programmes are largely absent or have started too recently to make reliable estimates of long-term trends. Discussion of the issue revolves disproportionately around honeybees, due to the more certain and ample data provided on the domesticated bees as well as their cultural importance. For instance, in testing impacts of insecticides on bees, high quality field 
tests are, as mentioned, a challenge, because given the complexity one expects inconsistency between field tests. As Maxim and Van der Sluijs (2013a) argued:

the complexity of environmental factors and of bee colonies means that the same field conditions can never be reproduced. A particular combination of such factors arising in a field experiment cannot be considered representative of "average" environmental conditions to which honeybees could be exposed.

As a consequence, regulatory decisions are unavoidably made based upon contradictory, flawed and missing data. Lack of information is, as such, only part of the problem. More information will also further highlight the complexity. The situation is indeed one of irreducible complexity, where the intricate entanglements of various environmental factors, manmade and natural, work together to affect the circumstances of pollinator species.

Despite the acknowledged uncertainties, consensus is growing that the global situation for pollinators is serious and needs regulatory and coordinated action on all levels from local to global (Goulson et al. 2015; Maxim and Van der Sluijs 2013a; Senapathi et al. 2015; UNEP 2010). Insect pollinators are deserving of increased attention due to their key ecosystem function of ensuring food security and biodiversity, and arguably due to the intrinsic value of each existing species and their relationships with other species in the ecosystems of which they form a key part.

Existing policies for pollinator conservation are highly fragmented, partial and uncoordinated. The issue of pollinator stewardship is cross cutting through many policy domains including the regulation of chemicals, agricultural policies, conservation policies, environmental policies and spatial planning policies. In terms of agency and what can and should be done by whom, it also cuts though all levels of governance, from very local (e.g., what citizens can do to make their garden pollinator friendly) to global (e.g., phasing out of certain chemicals and mitigating climate change). This poses major challenges to the coordinated effort that is needed to address an issue of such complexity.

\section{Proposed Solutions}

Internationally the UN Convention on Biodiversity covers all ecosystems, species and genetic resources. The Convention's Strategic Plan for Biodiversity 2011-2020 (CBD 2010) does not specifically refer to pollinators but it emphasises restoration of ecosystem services and habitats in general. Under the Convention, a major initiative for the Conservation and Sustainable Use of Pollinators has been established in 2002 and is coordinated by the FAO (2016).

In the context of pollinator conservation, the Convention's strategy has been criticised for solely building on human benefits from biodiversity as rationale for conservation (Senapathi et al. 2015; Kleijn et al. 2015). Too much focus on ecosystem services and economic value of pollinators ignores the potential value for future agriculture of species presently hardly contributing to crop pollination, fails to protect pollinators of wild plants and ignores the value of pollinator diversity and resilience and the intrinsic value of pollinators and plantpollinator relationships. The same holds true for, for instance, the EU biodiversity strategy (EC 2011), which only mentions pollination in terms of its economic benefits. Biological, moral and cultural arguments for pollinator conservation should complement the currently dominant economic arguments to achieve a more effective and holistic policy approach (Senapathi et al. 2015). 
Another important step at the international level has been the establishment of the Intergovernmental Science-Policy Platform on Biodiversity and Ecosystem Services (IPBES). IPBES is tasked with assessing the state of biodiversity and ecosystem services in response to requests from decision makers. The platform resides under UNEP, UNESCO, FAO and UNDP and is administered by UNEP. One of its first achievements has been the drafting of a thematic assessment on pollinators, pollination and food production, which at the time of finalisation of this manuscript was not yet publically available, but is expected to be published in the spring of 2016. It has been criticised for conflicts of interests of some of the authors (Hochkirch et al. 2014). Still, the priority that IPBES gave to initiating a thematic assessment on pollinators is a sign of the emerging realiation of the global importance of the pollinator issue, and is a first step towards a global vision to more efficiently cope with the situation.

In terms of what is needed to address the crisis, we will briefly discuss the different lines of action required. Primarily, the land use and landscape changes that led to the habitat destruction and depletion of floral and nesting resources need to be compensated by the reintroduction and conservation of micro-habitats for pollinators. This can be achieved by ecosystem restoration and promotion and further development of pollinator friendly agricultural practices and landscape management.

Ecosystem restoration practices that counteract nitrogen accumulation in soils of nature areas can increase floral biodiversity. In agricultural landscapes, hedgerows and field margins rich in native wild flowers and micro habitats suitable for nesting can be (re)introduced (Klein et al. 2007). Flowering trees in meadows can provide both shadow for grazing cattle and floral resources for pollinators. Citizens can place nesting boxes for wild bees and bumble bees in their gardens and can replace lawns and tiled areas by flower mixes for pollinators, for which special seed mixes are made available by nature conservation organisations. Bee friendly management of urban green areas (choice of plants as well as mowing and pruning practices) and road margins, creation of flowering green roofs and vertical gardens in the urban environment, pollinator highways in cities, urban beekeeping and urban farming can further contribute to the creation of both floral resources and nesting resources for wild bees (Baldock et al. 2015). Such initiatives are already undertaken in local contexts in Europe, Australia and the US, but at a small scale.

At present, mowing of road margins and pruning of trees (e.g., pollard willow) is often done before flowering, which unnecessarily reduces floral resources for pollinators. Promotion and development of pollinator friendly design and management of road and railway margins has a significant potential to increase floral and nesting resources. For instance, in the Netherlands a practice exists where all pollard willows are pruned every year before flowering. This can easily be changed into an alternating regime where half of the trees are pruned in the odd years and the others in the even years so that every other tree in a row of pollard willows will flower each spring. These regional measures can help counteract pollinator decline and strengthen resilience in the relevant areas. They will, however, not be sufficient to cope with the global situation of pollinator decline and its threat to future food security.

A global phase out on prophylactic use of agrochemicals and especially a total ban on all neonicotinoids and fipronil is required, along with the further development and promotion of organic farming and integrated pest management practices (Furlan and Kreutzweiser 2015). The creation of pesticide-free agricultural zones in the agricultural landscape can create habitats where pollinators threatened with extinction can survive during the long-term transition to global sustainable agriculture. 
Major shortcomings in the EU authorisation procedure of pesticides need to be addressed to ensure that effective pollinator protection has high priority in the authorisation tests (Maxim and Van der Sluijs 2013a). This is not unique for the EU but applies to authorisation procedures in virtually all counties around the globe. Testing for sub-lethal effects, long-term chronic toxicity and synergistic effects should be improved and should be afforded more weight. Exposure routes other than via nectar and pollen of treated plants should be included in the authorisation tests, such as exposure via wild plants (that translocate systemic pesticides from polluted soils and water to their pollen and nectar), surface water, soil, etc. Further, the testing regime should be modified in such a way that irreproducible field studies that do not show significant effects at the $p=0.05$ level, often considered as the limit for what is statistically significant, can no longer overrule reproducible findings from lab studies that demonstrate harm to bees and other pollinators at field realistic exposure levels.

Conflicts of interests in official risk assessment bodies and in the drafting of the tests to be used in the authorisation of pesticides are presently abundant and have contributed to the fact that present authorisation regimes have failed to protect pollinators. There is an urgent need to restore and maintain independence in regulatory science (Boone et al. 2014; Maxim and Van der Sluijs 2013a, b; Van der Sluijs et al. 2013b). Strong evidence underlies the recommendations from academic scientists for protection of pollinators as a core step in ensuring food security (Klein et al. 2007).

More targeted measures to reinforce pollinator-related food security have been suggested. For instance, crop flowering could be phenologically matched to pollinator lifecycles, and different groups of pollinators could be exploited, for instance through altering flowers' traits, such as colour and scent, as well as their life cycles (Bailes et al. 2015). Proposed solutions such as these, seeking to breed higher yielding crops that are also, and relatedly, more attractive to pollinators, need to be evaluated in a wider context of factors influencing the numbers of different pollinators with varying levels of resilience and vulnerability.

As with many other global environmental problems, techno fixes have also been proposed. These include the development of swarms of robotic insects that can pollinate flowers (Srinivasan 2011; Wyss Institute 2016), the spraying of chemicals and hormones that force fruit set in unpollinated flowers (Wright 2013), the use of crop varieties that set fruit without pollination (these are seedless, sterile fruits), the genetic engineering of wind-pollinated crops (cereals) to make these crops produce the micro nutrients that are now provided by pollinator mediated crops (e.g., golden rice that contains high levels of beta-carotene, a precursor of pro vitamin A, see Beyer 2010) and the breeding (or genetic engineering) of bees that are resistant to pesticides, parasites and pathogens (Schulte et al. 2014). For agricultural crops, hand pollination is also an option in some cases, but it is very labour intensive and in many cases not economically sustainable.

Each of the techno fixes has its own ethical challenges that go beyond the scope of the present paper, and only a few can be mentioned here: In addition to the caution that should be exercised regarding genetically modified insects and crops as they might cause unintended effects on the environment and local ecosystems, such fixes overlook the intrinsic value of existing species. GM agriculture has so far been used in large-scale mono crop agriculture, and may as such exacerbate the existing issue of industrial farming's impact on pollinator habitats. Hand pollination and techno fixes may, moreover, only work for agricultural impacts, not for the impacts of pollinator loss on nature areas and ecosystems at large. And the value of food diversity goes beyond nutritional value, into a complex realm of cultural appreciation, 
traditions, and taste. Pollinators, as argued in this paper, play a key role in perpetuating such diversity, which is vital for ensuring food security in the wide sense determined by the UN.

\section{Pollinator Stewardship, an International Challenge for Science and Policy}

Regional bans or stricter authorisation regimes are not sufficient to counteract the decline in pollinator activity and potential species loss. The present pollinator crisis is pressing and urgent. It threatens global and local food security, can worsen the problems of hidden hunger and can destabilise ecosystems that form our life support system. To respond to this crisis an integrated approach aimed at global pollinator stewardship and restoration of floral, nesting and micro-habitat resources is needed (Vanbergen and the Insect Pollinators Initiative 2013). The knowledge infrastructure required to support global pollinator stewardship needs to be strengthened. IPBES can play a further role here, but investments are also needed in interdisciplinary research aimed at better understanding of trends and interacting drivers of pollinator decline as well as development of new and improved options for restoration of floral and nesting resources and micro-habitats. Development of pollinator friendly landscape management and agricultural practices should be promoted. While some important steps have been made in recent years, particularly in the EU, the current regulations at the national and regional levels at present do not have the scope and aims to efficiently protect pollinators against the accumulating hardships of pesticides, habitat loss and climate change. Given the complexity of the issue and the global nature of the problem of pollinator decline, concerted effort is needed. It is time to initiate an international treaty for global pollinator protection and pollinator ecosystem restoration. Such a treaty would include global phase out of the prophylactic use of ecotoxic agrochemicals such as neonicotinoids and fipronil, and agreement on measures to conserve and restore pollinator habitats, considering the core importance of these insect species for ecosystem resilience and human food security and acknowledging their intrinsic value.

\section{References}

Aizen, Marcelo A., and Lawrence D. Harder. 2009. The global stock of domesticated honey bees is growing slower than agricultural demand for pollination. Current Biology. doi:10.1016/j.cub.2009.03.071.

Allen-Wardel, Gordon, et al. 1998. The potential consequences of pollinator declines on the conservation of biodiversity and stability of food crop yields. Conservation Biology. doi:10.1111/j.1523-1739.1998.97154.x.

Bailes, Emily J., et al. 2015. How can an understanding of plant-pollinator interactions contribute to global food security? Current Opinion in Plant Biology. doi:10.1016/j.pbi.2015.06.002.

Baldock, Katherine C.R., et al. 2015. Where is the UK's pollinator biodiversity? The importance of urban areas for flower-visiting insects. Proceedings of the Royal Society B. doi:10.1098/rspb.2014.2849.

Banskota, Arjun H., Yasuhiro Tezuka, and Shigetoshi Kadota. 2001. Recent progress in pharmacological research of propolis. Phytotherapy Research. doi:10.1002/ptr.1029.

Benadi, Gita, et al. 2013. When can plant-pollinator interactions promote plant diversity? The American Naturalist. doi:10.1086/670942.

Berry, Elliot M., et al. 2015. Food security and sustainability: can one exist without the other? Public Health Nutrition. doi:10.1017/S136898001500021X.

Beyer, Peter. 2010. Golden rice and 'Golden' crops for human nutrition. New Biotechnology. doi:10.1016/j.nbt. 2010.05.010.

Biesmeijer, Jacobus C., et al. 2006. Parallel declines in pollinators and insect-pollinated plants in Britain and the Netherlands. Science. doi:10.1126/science.1127863.

Bijleveld van Lexmond, Maarten, et al. 2015. Worldwide integrated assessment on systemic pesticides. Environmental Science and Pollution Research. doi:10.1007/s11356-014-3220-1. 
Bloch, Guy, et al. 2010. Industrial apiculture in the Jordan valley during Biblical times with Anatolian honeybees. Proceedings of the National Academy of Sciences of the United States of America. doi:10.1073/pnas. 1003265107.

Bobbink, R., et al. 2010. Global assessment of nitrogen deposition effects on terrestrial plant diversity: a synthesis. Ecological Applications. doi:10.1890/08-1140.1.

Bonmatin, J.-M., et al. 2015. Environmental fate and exposure; neonicotinoids and fipronil. Environmental Science and Pollution Research. doi:10.1007/s11356-014-3332-7.

Boone, Michelle D., et al. 2014. Pesticide regulation amid the influence of industry. BioScience. doi:10.1093/ biosci/biu138.

Botías, Cristina, et al. 2015. Neonicotinoid residues in wildflowers, a potential route of chronic exposure for bees. Environmental Science \& Technology. doi:10.1021/acs.est.5b03459.

Breeze, T.D., et al. 2011. Pollination services in the UK: how important are honeybees? Agriculture, Ecosystems \& Environment. doi:10.1016/j.agee.2011.03.020.

Buchmann, Stephen L., and Gary Paul Nabhan. 1997. The forgotten pollinators. Washington, DC: Island Press.

Cameron, Sydney A., et al. 2011. Patterns of widespread decline in North American bumble bees. Proceedings of the National Academy of Sciences of the United States of America. doi:10.1073/pnas.1014743108.

CBD. 2010. Strategic plan for biodiversity 2011-2020 and the Aichi biodiversity targets. Convention of biological diversity http://www.cbd.int/decision/cop/?id=12268. Accessed 12 Mar 2016.

Chagnon, Madeleine, et al. 2015. Risks of large-scale use of systemic insecticides to ecosystem functioning and services. Environmental Science and Pollution Research International. doi:10.1007/s11356-014-3277-x.

Conradt, Larissa, and Timothy J. Roper. 2005. Consensus decision making in animals. Trends in Ecology and Evolution. doi:10.1016/j.tree.2005.05.008.

CST. 2003. Imidaclopride utilisé en enrobage de semences (Gaucho®) et troubles des abeilles, rapport final, Comité scientifique et technique de l'étude multifactorielle des troubles des abeilles. Paris: CST.

Cutler, G. Christopher, and Cynthia D. Scott-Dupree. 2007. Exposure to clothianidin seed-treated canola has no long-term impact on honey bees. Journal of Economic Entomology. doi:10.1603/0022-0493(2007)100.

Dams, Lya R. 1978. Bees and honey-hunting scenes in the mesolithic rock art of Eastern Spain. Bee World. doi: 10.1080/0005772X.1978.11097692.

EASAC. 2015. Ecosystem services, agriculture and neonicotinoids. Halle: European Academies Science Advisory Council.

Ebert, Adam. 2011. Nectar for the taking: the popularization of scientific bee culture in England, 1609-1809. Agricultural History 85: 322-343.

EC. 2011. Our life insurance, our natural capital: an EU biodiversity strategy to 2020. COM (2011) 244 final, Brussels. http://eur-lex.europa.eu/legal-content/EN/TXT/PDF/?uri=CELEX:52011DC0244\&from=EN. Accessed 12 Mar 2016.

EFSA. 2013. Guidance on the risk assessment of plant protection products on bees (Apis mellifera, Bombus spp. and solitary bees). EFSA Journal 11(7): 3295.

EFSA. 2015. Risk to bees from fipronil: call for data. http://www.efsa.europa.eu/en/press/news/150901. Accessed 13 Mar 2015.

Ehrlich, Paul R., and John Harte. 2015. Opinion: to feed the world in 2050 will require a global revolution. Proceedings of the National Academy of Sciences of the United States of America. doi:10.1073/pnas. 1519841112.

Eilers, Elisabeth J., et al. 2011. Contribution of pollinator-mediated crops to nutrients in the human food supply. PLoS One. doi:10.1371/journal.pone.0021363.

Ellis, Hattie. 2014. Spoonfuls of honey. A complete guide to honey's flavours \& culinary uses with over 80 recipes. London: Pavilion Books.

Ellis, Alicia M., Samuel S. Myers, and Taylor H. Ricketts. 2015. Do pollinators contribute to nutritional health? PLoS One. doi:10.1371/journal.pone.0114805.

FAO. 1996. Rome declaration on food security and world food summit plan of action. Rome: FAO.

FAO. 2016. FAO's global action on pollination services for sustainable agriculture. http://www.fao.org/ pollination/projects/en/. Accessed 17 Mar 2016.

Furlan, Lorenzo, and David Kreutzweiser. 2015. Alternatives to neonicotinoid insecticides for pest control: case studies in agriculture and forestry. Environmental Science and Pollution Research International. doi:10. 1007/s11356-014-3628-7.

Gallai, Nicola, et al. 2009. Economic valuation of the vulnerability of world agriculture confronted with pollinator decline. Ecological Economics. doi:10.1016/j.ecolecon.2008.06.014.

Goulson, Dave. 2015. Neonicotinoids impact bumblebee colony fitness in the field; a reanalysis of the UK's Food \& Environment Research Agency 2012 experiment. PeerJ. doi:10.7717/peerj.854.

Goulson, Dave, et al. 2015. Bee declines driven by combined stress from parasites, pesticides, and lack of flowers. Science. doi:10.1126/science.1255957. 
Hochkirch, Axel, Philip J.K. McGowan, and Jeroen Van der Sluijs. 2014. IPBES must address conflicts of interest. Nature. doi:10.1038/516170c.

IFPRI. 2014. Global hunger index. Washington, DC: International Food Policy Research Institute. http://www. ifpri.org/node/538. Accessed 7 January 2016.

Jeschke, Peter, and Ralf Nauen. 2008. Neonicotinoids - from zero to hero in insecticide chemistry. Pest Management Science. doi:10.1002/ps.

Jeschke, Peter, et al. 2011. Overview of the status and global strategy for neonicotinoids. Journal of Agricultural and Food Chemistry. doi:10.1021/jf101303g.

Jull, Andrew B., Anthony Rodgers, and Natalie Walker. 2008. Honey as a topical treatment for wounds. The Cochrane Database of Systematic Reviews. doi:10.1002/14651858.CD005083.pub2.

Kevan, Peter G., and Randolf Menzel. 2012. The plight of pollination and the interface of neurobiology, ecology and food security. The Environmentalist. doi:10.1007/s10669-012-9394-5.

Klatt, Björn K., et al. 2014. Bee pollination improves crop quality, shelf life and commercial value. Proceedings. Biological sciences / The Royal Society.. doi:10.1098/rspb.2013.2440.

Kleijn, David, et al. 2015. Delivery of crop pollination services is an insufficient argument for wild pollinator conservation. Nature Communications. doi:10.1038/ncomms8414.

Klein, Alexandra-Maria, et al. 2007. Importance of pollinators in changing landscapes for world crops. Proceedings. Biological sciences / The Royal Society. doi:10.1098/rspb.2006.3721.

Krupke, Christian H., and Elizabeth Y. Long. 2015. Intersections between neonicotinoid seed treatments and honey bees. Current Opinion in Insect Science. doi:10.1016/j.cois.2015.04.005.

Maus, Christian, and Ralf Nauen. 2011. Response to the publication: Tennekes, H.A. (2010): the significance of the Druckrey-Küpfmüller equation for risk assessment-The toxicity of neonicotinoid insecticides to arthropods is reinforced by exposure time. Toxicology 280: 176-177. doi:10.1016/j.tox.2010.11.014.

Maxim, Laura, and Jeroen P. van der Sluijs. 2007. Uncertainty: cause or effect of stakeholders' debates? Analysis of a case study: the risk for honeybees of the insecticide Gaucho ${ }^{\circledR}$. Science of the Total Environment. doi:10. 1016/j.scitotenv.2006.12.052.

Maxim, Laura, and Jeroen P. van der Sluijs. 2010. Expert explanations of honeybee losses in areas of extensive agriculture in France: Gaucho ${ }^{\circledR}$ compared with other supposed causal factors. Environmental Research Letters. doi:10.1088/1748-9326/5/1/014006.

Maxim, Laura, and Jeroen P. van der Sluijs. 2013a. Seed-dressing systemic insecticides and honeybees. In Late lessons from early warnings: science, precaution, innovation. 401-438, ed. European Environment Agency. European Environment Agency (EEA) report 1/2013, Copenhagen.

Maxim, Laura, and Jeroen P. van der Sluijs. 2013b. Response to the Bayer Cropscience (Richard Schmuck) comments on the chapter. In Late lessons from early warnings II: bee decline web debate, ed. European Environment Agency, 8-20. http://www.eea.europa.eu/publications/late-lessons-2/late-lessons-chapters/ bees-insecticides-debate. Accessed 17 Mar 2016.

Nicole, Wendee. 2015. Pollinator power: nutrition security benefits of an ecosystem service. Environmental Health Perspectives 123: A210-A215.

Ollerton, Jeff, Rachael Winfree, and Sam Tarrant. 2011. How many flowering plants are pollinated by animals? Oikos. doi:10.1111/j.1600-0706.2010.18644.x.

Partap, Uma, and Tang Ya. 2012. The human pollinators of fruit crops in Maoxian County, Sichuan, China. A case study of the failure of pollination services and farmers' adaptation strategies. Mountain Research and Development. doi:10.1659/MRD-JOURNAL-D-11-00108.1.

Pattinson, David. 2012. Pre-modern beekeeping in China: a short history. Agricultural History 86: $235-255$.

Pearson, Richard G. 2016. Reasons to conserve nature. Trends in Ecology \& Evolution. doi:10.1016/j.tree.2016. 02.005 .

Pisa, L.W., et al. 2015. Effects of neonicotinoids and fipronil on non-target invertebrates. Environmental Science and Pollution Research. doi:10.1007/s11356-014-3471-x.

Potts, Simon G., et al. 2010. Global pollinator declines: trends, impacts and drivers. Trends in Ecology \& Evolution. doi:10.1016/j.tree.2010.01.007.

Rader, Romina, et al. 2015. Non-bee insects are important contributors to global crop pollination. Proceedings of the National Academy of Sciences. doi:10.1073/pnas.1517092112.

Rogers, Janine, and Charlotte Sleigh. 2012. Here is my honey-machine: Sylvia Plath and the mereology of the Beehive. The Review of English Studies 63: 293-310.

Runckel, Charles, et al. 2011. Temporal analysis of the honey bee microbiome reveals four novel viruses and seasonal prevalence of known viruses, Nosema, and Crithidia. PLoS One. doi:10.1371/journal.pone. 0020656.

Rundlöf, Maj, et al. 2015. Seed coating with a neonicotinoid insecticide negatively affects wild bees. Nature. doi: 10.1038 /nature 14420 .

Sanchez-Bayo, Francisco. 2014. The trouble with neonicotinoids. Science. doi:10.1126/science.1259159. 
Schulte, Christina, et al. 2014. Highly efficient integration and expression of piggyBac-derived cassettes in the honeybee (Apis mellifera). PNAS. doi:10.1073/pnas.1402341111.

Senapathi, Deepa, et al. 2015. Pollinator conservation - The difference between managing for pollination services and preserving pollinator diversity. Current Opinion in Insect Science. doi:10.1016/j.cois.2015.11.002.

Simon-Delso, Noa, et al. 2015. Systemic insecticides (neonicotinoids and fipronil): trends, uses, mode of action and metabolites. Environmental Science and Pollution Research. doi:10.1007/s11356-014-3470-y.

Southwood, T., and E. Richard. 1977. Entomology and mankind: insects over the ages have greatly affected man's health and food supply and have played an important role as religious and cultural symbols. American Scientist 65: 30-39.

Srinivasan, Mandyam V. 2011. Honeybees as a model for the study of visually guided flight, navigation, and biologically inspired robotics. Physiological Reviews. doi:10.1152/physrev.00005.2010.

Suchail, S., D. Guez, and L.P. Belzunces. 2001. Discrepancy between acute and chronic toxicity induced by imidacloprid and its metabolites in Apis mellifera. Environmental Toxicology and Chemistry 20: 2482-2486.

Tennekes, Henk A. 2010. The significance of the Druckrey-Küpfmüller equation for risk assessment - The toxicity of neonicotinoid insecticides to arthropods is reinforced by exposure time. Toxicology 280: 176-177. doi:10.1016/j.tox.2010.07.005.

Tennekes, Henk A., and Francisco Sanchez-Bayo. 2011. Time-dependent toxicity of neonicotinoids and other toxicants: implications for a new approach to risk assessment. Journal of Environmental \& Analytical Toxicology. doi:10.4172/2161-0525.S4-001.

Tennekes, Henk A., and Francisco Sánchez-Bayo. 2013. The molecular basis of simple relationships between exposure concentration and toxic effects with time. Toxicology. doi:10.1016/j.tox.2013.04.007.

UNEP. 2010. Global honey bee colony disorders and other threats to insect pollinators. UNEP emerging issues report, United Nations Environmental Program, Nairobi.

UNEP. 2011. Bees under bombardment: report shows multiple factors behind pollinator losses, Press release 10 March 2011, United Nations Environmental Program, Nairobi. http://www.unep.org/Documents. Multilingual/Default.Print.asp?DocumentID=664\&ArticleID=6923. Accessed 28 Dec 2015.

Van der Sluijs, Jeroen P., J. Arjan Wardekker, and Ilectra Kouloumpi. 2013a. Sustainability and product risks: identifying and preventing risk migration. Report in commission of the Netherlands Food and Consumer Product Safety Authority (NVWA). Utrecht: Copernicus Institute, Utrecht University. http://epinet.no/sites/all/ themes/epinet_bootstrap/documents/van_der_sluijs\%20et_al_2013.pdf. Accessed 28 Dec 2015.

Van der Sluijs, Jeroen P., et al. 2013b. Neonicotinoids, bee disorders and the sustainability of pollinator services. Current Opinion in Environmental Sustainability. doi:10.1016/j.cosust.2013.05.007.

Van der Sluijs, Jeroen P., et al. 2015. Conclusions of the worldwide integrated assessment on the risks of neonicotinoids and fipronil to biodiversity and ecosystem functioning. Environmental Science and Pollution Research. doi:10.1007/s11356-014-3229-5.

Van Dijk, Tessa C., Marja A. Van Staalduinen, and Jeroen P. van der Sluijs. 2013. Macro-invertebrate decline in surface water polluted with imidacloprid. PLoS One. doi:10.1371/journal.pone.0062374.

Vanbergen, Adam J., and the Insect Pollinators Initiative. 2013. Threats to an ecosystem service: pressures on pollinators. Frontiers in Ecology and the Environment. doi:10.1890/120126.

Williams, Geoffrey R., et al. 2015. Neonicotinoid pesticides severely affect honey bee queens. Nature Scientific Reports. doi:10.1038/srep14621.

Wright, C.J. 2013. Manipulation of fruiting. London: Butterworths.

Wyss Institute. 2016. The RoboBees project and colony collapse disorder. http://wyss.harvard.edu/viewpage/536. Accessed 17 Mar 2016. 